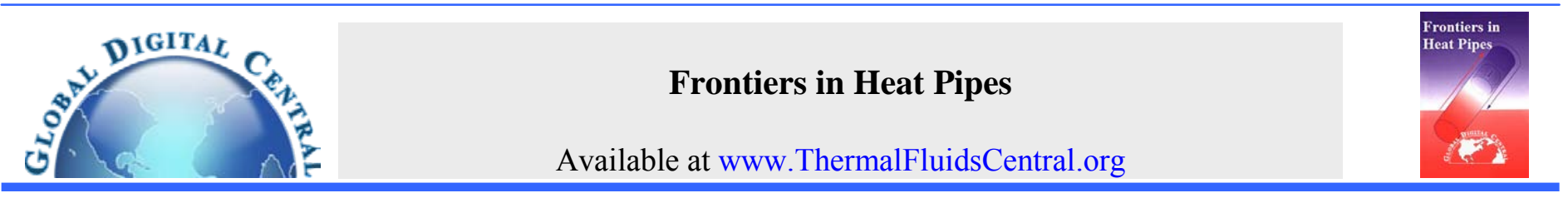

\title{
AN INVESTIGATION ON LIGHTWEIGHT MAGNESIUM ALLOY HEAT PIPES
}

\author{
Xiao Yang ${ }^{\mathrm{a}, \mathrm{b}}$, Yuying Yan $^{\mathrm{a}, \dagger}$, Ryan J. McGlen ${ }^{\mathrm{b}}$ \\ ${ }^{a}$ Energy and Sustainability Research Division, Faculty of Engineering, The University of Nottingham, Nottingham, NG7 2RD, UK \\ ${ }^{b}$ Thermacore Europe Ltd., Ashington, Northumberland, NE63 8QW, UK
}

\begin{abstract}
The increasing demand for "lightweight" has become key goals for the development of next generation heat pipes for space and aerospace applications. Axially grooved aluminium heat pipes have served for spacecraft thermal management systems for nearly thirty years. Due to a typical launch cost on the order of $\$ 10,000$ per pound of spacecraft mass, magnesium alloys have been investigated as alternatives to aluminium. The present study has investigated the wettablity and phase change on the magnesium alloy surface. The pool nucleate boiling performance of acetone, ethanol and their mixtures is studied experimentally. Fundamental contact angle tests are also presented.
\end{abstract}

Keywords: Magnesium alloy, lightweight heat pipe, space, aerospace.

\section{INTRODUCTION}

Heat pipes are widely used in many areas, such as in electronic device cooling systems, aerospace industry, telecommunication industry, food industry, etc. Over the past decade, researchers have paid more attentions to developing lightweight heat pipes. According to a report by NASA (Rosenfeld and Zarembo, 2001), reducing one pound of weight on a spacecraft can help to save $\$ 10,000$ US dollars in launch costs. Moreover, a telecommunication satellite may require more than one hundred heat pipes (Hoa et al., 2003). Rather than save the cash on the launch cost, another option is to add additional electronics payload to the satellite to maintain the overall mass. Over time the revenue generated by the additional electronics will be much more than the saving in fuel costs. Therefore, considering the huge benefits, "lightweight" has become a high priority goal for current heat pipe designs, especially for space and aerospace applications.

So far, many materials have been used in such investigations, including aluminium alloys, beryllium-based alloys, titanium alloys, epoxy-impregnated carbon fibre wound over thin aluminium shells, laminate materials, metal/matrix composites and magnesium alloys (Rosenfeld and Zarembo, 2001). However, only aluminium alloy heat pipes have been applied extensively in the market, due to the manufacture, compatibility and cost issues. To improve the lightweight heat pipes, in recent years, the investigations have extended to explore if magnesium $(\mathrm{Mg})$ alloys could also be used for manufacturing heat pipes or vapour chambers, and the study of magnesium-ammonia heat pipes has been reported (Rosenfeld and Zarembo, 2001). Indeed, magnesium with a density of $1738 \mathrm{~kg} / \mathrm{m}^{3}$ is often regarded as one of the lightest metals in the world. With nearly half the density of aluminium, but with similar thermal and mechanical properties, magnesium and its alloys have significant potential to be used as a h eat pipe container material (Yang, Yan and Mullen, D., 2012). As magnesium alloys available in the market today have densities about $1800 \mathrm{~kg} / \mathrm{m}^{3}$ and a range of thermal conductivity of 80 to $130 \mathrm{~W} / \mathrm{m} \cdot \mathrm{K}$, studies focusing on using magnesium alloys for manufacturing heat pipes have become very popular and attractive (Markar and Kruger, 1993; Avedesian and Baker, 1999).

Previous studies (Yang and Yan, 2011; Yan and Ji, 2008) show that water is incompatible with magnesium alloys without the surface protection, but pure acetone and ethanol are compatible with the alloys. In this paper, the following fundamental issues such as the heat transfer performance of the working fluid on $\mathrm{m}$ agnesium alloy surface, the surface wettabilities, etc. are studied. Pool nucleate boiling experiments are carried out to predict the phase change process and thermal performance of pure acetone, ethanol and their mixtures on the magnesium alloy surface in heat pipe. Moreover, the contact angles of different working fluids on the magnesium surface are measured to study the wettability of the fluids and to predict the capillary effects of grooved surfaces on the fluids and therefore to help achieve the high capacity demanded of the heat pipes design.

\section{METHODOLOGIES}

\subsection{Pool Boiling of Mixtures}

According to recent literature, it can be seen that more and more people have paid attention to research associated with binary or multicomponents boiling processes, in order to get a better understanding of phase change of mixtures. Focusing on binary system, such as acetonewater, ethanol-water and methanol water mixtures, Thome (1987) carried out many numerical and experimental studies and found that the mixture boiling correlation for conventional smooth heated surface is not suitable for predicting the boiling performance of an enhanced heated surface. Rao and Balakrishnan (2004) used acetone-isopropanolwater and acetone-MEK (methyl ethyl ketone)-water ternary system to do the pool boiling experiments, and found that the heat transfer coefficients of the mixtures were lower than interpolated values among the pure components. Inoue et al. (2002) carried out nucleate boiling experiments by using ammonia/water mixture to predict the boiling

\footnotetext{
† Corresponding author, Professor Y.Y. Yan, Email: yuying.yan@nottingham.ac.uk, Tel : +44 (0) 1159513168.
} 
process based on existing correlations, and found the heat transfer coefficient of the binary components was smaller compared with the pure components. Táboas et al. (2007) chose ammonia/water mixtures and produced similar results as in the literature, and proposed a new correlation for this mixture system. Gorenflo et al. (2001) investigated the mixtures of water/l-butanol on a heated copper surface and the miscibility gap of the binary system. Typically, in recent years, the research (Fujita et al., 2004; Zhang et al., 2007; Zhao et al., 2008) into the boiling of refrigerant mixtures have become popular and attractive. Fujita and Tsutsui (2004) reported that heat transfer coefficients of refrigerant mixtures (R-134a, R-142b and R-123) are less than the interpolated values of pure components. Also they made the correlations for the refrigerants based on their correlation equations. Zhang et al. (2007) measured HC170/HFC23 binary system in nucleate pool boiling experiments and compared the results with Jungnickel et al. (1980) correlations. Zhao et al. (2008) conducted experimental studies on both non-azeotrope and azeotrope mixtures, including HFC32/134a, HFC-32/125, and their pure components.

A number of investigations (Thome 1987; Rao and Balakrishnan, 2004; Inoue et al., 2002; Táboas et al., 2007; Gorenflo et al., 2001; Neve and Yan, 1996; Fujita and Tsutsui, 2004; Zhang et al., 2007) have experimentally determined the heat transfer coefficients associated with nucleate boiling of various binary mixtures. Such experiments usually consist of a s eries of steady-state boiling tests at liquid compositions ranging from a single pure fluid to a single second pure fluid, while keeping other conditions constant. The boiling curve for a binary mixture is described in (Collier and Thome, 1994), as shown in Fig. 1.

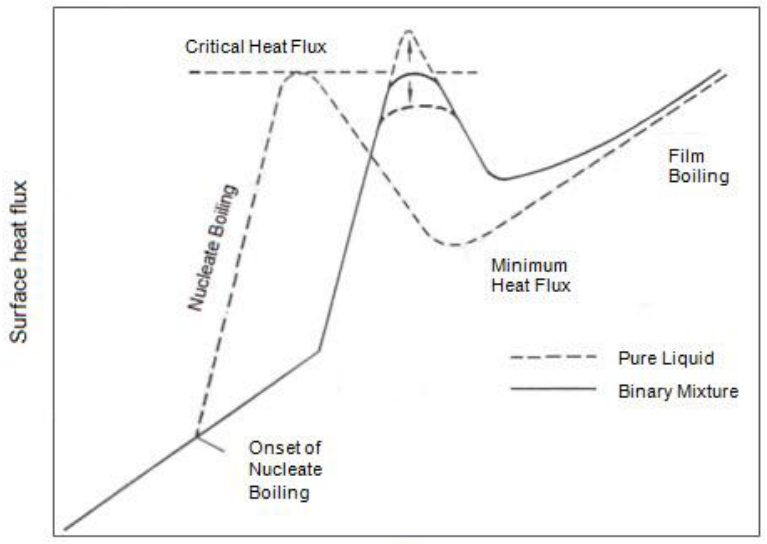

$\Delta \mathrm{T}_{\text {sat }}$

Fig. 1 Mixture boiling curve of the binary system.

For these experiments, a h eat transfer coefficient $h_{b l}$ is often defined as (Carey, 2008):

$$
h_{b l}=\frac{q^{\prime \prime}}{\left[T_{W}-T_{b p}\left(P_{l}, \widetilde{x}_{l}\right)\right]}
$$

where $T_{w}$ is the wall temperature and $T_{b p}\left(P_{l}, \tilde{x}_{l}\right)$ is the bubble point temperature at the liquid pressure $P_{l}$ and mole fraction in liquid phase $\widetilde{X}_{l}$.

When vaporisation occurs in a non-azeotropic binary mixture, the vapour generated is richer in the more volatile component than the bulk liquid, and the remaining liquid in the vicinity of the interface has correspondingly lower concentration of the more volatile component. Eventually, in the liquid phase, the more volatile component diffuses towards the interface, and the excess less volatile component diffuses away from the interface into the bulk liquid. If diffusion in the liquid were infinitely fast, the interface concentration would equal that in the bulk liquid. As far as heat transfer is concerned, the mixture would then behave essentially like an azeotropic mixture. For such idealised circumstances, a plausible estimate of the heat transfer coefficient $h_{b l i}$ would be a weighted average of the heat transfer coefficients for the pure components. A straight forward method would be to define $h_{b l i}$ as the mole fraction weighted average of single component nucleate boiling heat transfer coefficients for the pure components at the system pressure (Carey, 2008).

$$
h_{b l i}=h_{b 1} \widetilde{x}_{l}+h_{b 2}\left(1-\widetilde{x}_{l}\right)
$$

where $h_{b 1}$ and $h_{b 2}$ are the pure component heat transfer coefficients at the same pressure and heat flux for the low boiling point and high boiling point constituents, respectively.

The current binary mixture (acetone/ethanol), belongs to the nonazeotrope family of mixtures which have a simpler boiling process than the azeotrope mixtures. The saturation point of the binary mixture can be determined from the relevant equilibrium phase diagram. In terms of the acetone/ethanol mixture boiling process, the mole fraction is used to determine the partial pressure, saturation temperature and so on.

According to the experiments of $\mathrm{Tu}$ and $\mathrm{Ku}$ (2005) the acetone/ethanol vapour-liquid equilibrium phase diagram is presented, as shown in Fig. 2, at a constant atmospheric pressure of $101.3 \mathrm{kPa}$. Two curves are shown in the diagram; one is the dew-point curve and the other is the bubble-point curve. The dew-point curve shows the condensation starting points of vapour phase of the mixture, of different concentrations; and the bubble-point curve indicates the state of liquid phase of the mixture starting to evaporate at the bubble point. It can be seen from the diagram that, the saturation point of the binary mixture is easy to be identified based on the mole fraction, and this is useful for determining heat transfer coefficient in the following calculations.

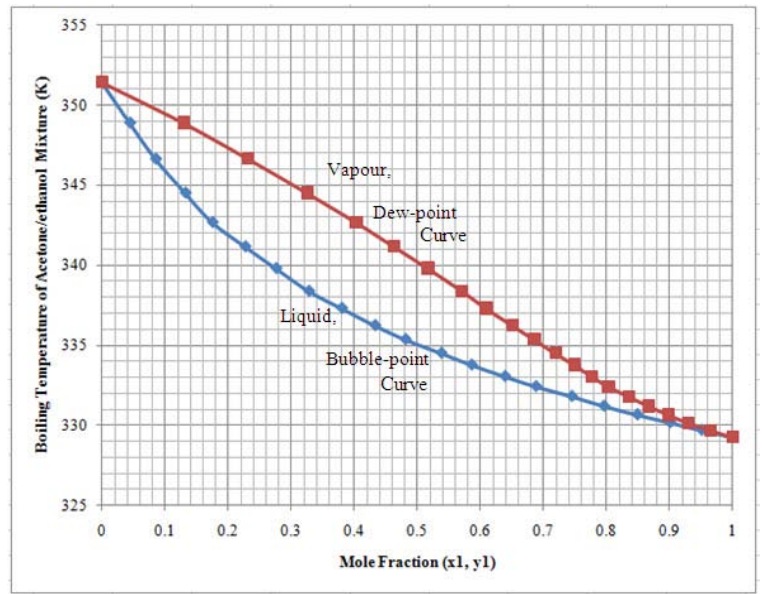

Fig. 2 Equilibrium phase diagram of acetone/ethanol mixture under the pressure of $101.3 \mathrm{kPa}$.

\subsection{Basic Theories of Wetting Phenomenon}

Regarding the design of a heat pipe, the following factors are very important when identifying a suitable working fluid: compatibility, thermal stability, wettability, vapour pressure, latent heat, thermal conductivity, liquid and vapour viscosities, surface tension and freezing point (Reay and Kew 2006).

\subsubsection{Basic theories of wetting phenomenon inside the heat pipes}

For a heat pipe, it is necessary for the working fluid to wet the wick and wall/container materials (Reay and Kew 2006). Contact angle as an important parameter, it quantifies the wetting phenomenon of the liquid during the heat pipe operation. Generally, when a contact angle $(\theta)$ value is in range of $0^{\circ}$ to $\pi$, it is called "wetting" surface or hydrophilic; when this value is above $\pi$ and up to g, 8 hen it is "non -wetting" 
surface status or called hydrophobic (see Fig. 3). Also complete "wetting" and "non-wetting" occurs at $\theta=0^{\circ}$ and $\theta=180^{\circ}$ respectively.

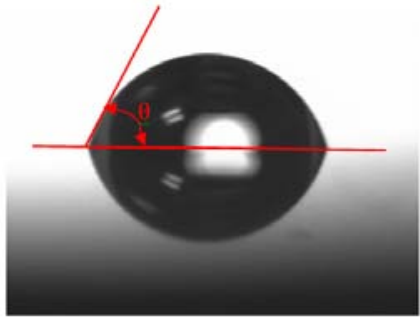

(a) $0^{\circ}<\theta<\pi$, wetting

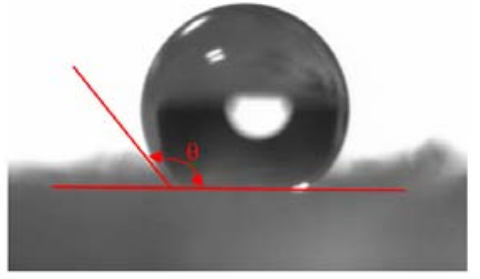

(b) $\pi<\theta<180^{\circ}$, non-wetting
Fig. 3 Profile shapes of liquid droplets on solid surfaces: (a) DI water on polished copper surface; (b) DI water on Polydimethylsiloxane (PDMS) surface.

According to the Young's equation (Gao and Yan, 2009), contact angle is defined as:

$$
\cos \theta=\frac{\sigma_{s v}-\sigma_{s l}}{\sigma_{l v}}
$$

where $\sigma_{s v}, \sigma_{s l}$ and $\sigma_{l v}$ are interfacial surface tensions at solid-vapour interface, solid-liquid interface and liquid-vapour interface respectively. The system boundary of these three interfaces is presented in Fig. 4. Regarding Young's model, it applies to an ideal situation, which the solid substrate surface should be under the conditions of chemical homogeneity, rigid, smooth, and free from chemical interaction by liquid or vapour adsorption (Erbil et al., 1999).

For common heat pipes operating in non-horizontal orientations, they function based on the capillary-driven system that allows the working fluid to circulate. Moreover, the difference in curvature of evaporating and condensing liquid-vapour interfaces might affect the capillary-driven system. Consequently, it can have a significant effect on the heat pipe capacity and performance. At the microscopic scale, a liquid-vapour interface can be defined as a volumetric transition zone across which the molecule number density varies continuously; and under the macroscopic scale, an interface between a 1 iquid and its vapour can be described by surface tension, which is defined thermodynamically as the change in surface excess free energy per unit increase in interfacial area (Ochterbeck, 2003):

$$
\sigma=\left(\frac{\partial E}{\partial A_{s}}\right)_{T, n}
$$

where $\mathrm{E}$ is the total energy, $\mathrm{J}$; $\mathrm{A}$ is the area, $\mathrm{m}^{2}$; and $\sigma$ is the surface tension, $\mathrm{N} / \mathrm{m}$.

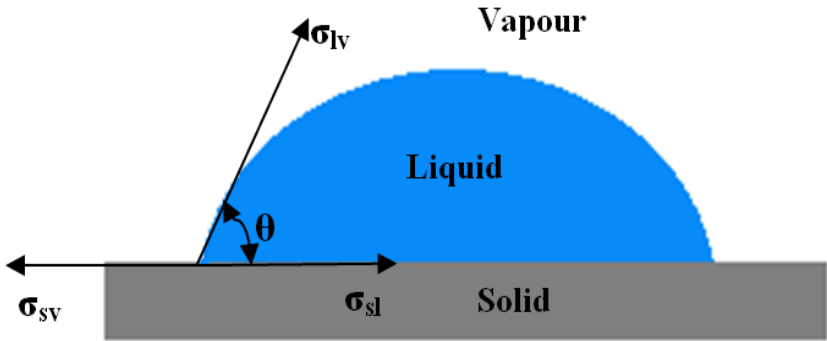

Fig. 4 Sketch of a contact angle of a liquid droplet.

In heat pipe, the capillary lift rises with an increase of liquid surface tension and decreasing of contact angle (Hewitt, Shires and Bott, 1993). Taking the vertical orientation of a heat pipe as an example; its pressure balance can be described as:

$$
\Delta P_{c}=\frac{2 \sigma_{l}}{R} \cos \theta
$$

where $\Delta P$ is the capillary pressure drop; $\mathrm{Pa}, \sigma_{l}$ is the surface tension of liquid-vapour interface, $\mathrm{N} / \mathrm{m}$; $\mathrm{R}$ is radius of the wick, mm; and $\theta$ is contact angle, ${ }^{\circ}$. Therefore, when the value of $\theta$ is tending to $0(\theta \rightarrow 0)$, it will reach the maximum capillary pressure, and then the heat pipe capacity will achieve a maximum value as well.

\subsubsection{Measurement techniques}

The contact angles are normally classified as static and dynamic angles. The measurement of the static contact angle analysis is most commonly based on an individual droplet, which uses an image captured from substrate surface to calculate the contact angle value (Heiskanen et al., 2008). In terms of the dynamic contact angle measurement, it is more complicated than the static measurement, and it measures the moving droplets, thus, some factors might affect the obtained results of contact angles, such as the velocity of the liquid plug and variations caused by surface properties (Heiskanen et al., 2008). In this study, consideration is given only to measuring the static contact angles.

According to the literatures (Heiskanen et al., 2008; Shang et al., 2008; Vadgama and Harris, 2007; Neumann and Good, 1979; Krishnan et al., 2005), several methods have been used for contact angle measurements on a solid surface, including the sessile drop, Wilhelmy plate, tilting plate and so on. As for the sessile drop method, it is the most popular one and widely used where it can measure both static and dynamic contact angles, but generally requires the substrate to have a flat surface (Heiskanen et al., 2008; Shang et al., 2008). Generally, based on this method, the contact angle of a working fluid is determined by a telescope, equipped with a goniometer eyepiece or by capturing an image and then calculating the value later (Vadgama and Harris, 2007). Although the sessile drop method is suitable for measuring both small and large droplet sizes, for most working fluids, compared with other methods, it cannot give accurate results. In the early works by Neumann and Good (1979, cited by Vadgama and Harris, 2007), they pointed out that there is an overall error of $\pm 2^{\circ}$ for the sessile drop method.

Regarding the Wilhelmy plate method, it is commonly used for materials with a well-defined wetting length, and then the contact angle measurement is calculated by capillary force (Shang et al., 2008), which is expressed as follow (Neumann and Good, 1979, cited by Vadgama and Harris, 2007):

$F=P \sigma_{s l} \cos \theta-\Delta \rho g V+m g$

where $\mathrm{P}$ is the perimeter of the plate, $\mathrm{m} ; \sigma_{\mathrm{sl}}$ is the liquid surface tension, $\mathrm{N} / \mathrm{m} ; \mathrm{V}$ is the volume of liquid displaced, $1 ; \mathrm{m}$ is the mass of the plate, $\mathrm{kg} ; \Delta \rho$ is the density difference between the fluid's liquid phase and the surrounding ambient, $\mathrm{kg} / \mathrm{m}^{3}$. According to previous works (Neumann and Good, 1979 cited by Vadgama and Harris, 2007), the Wilhelmy plate method can give very accurate measuring results, where the measurement is based on the measuring force and relevant calculations instead of measuring an angle directly. However, there is a disadvantage to this method, where the reproducibility of the measurements is easily affected by the plate geometry and composition.

In terms of the tilting plate method, it is one of the goniometric methods which are widely applied in commercial instruments to measure contact angles (Cwikel et al., 2010). As for this method, commonly there is a plate partially immersed in the liquid and the meniscus is formed at both faces of the plate (Vadgama and Harris, 2007). Then the left and right sides of a droplet are measured and the surface is tilted with respect to the optical axis until the liquid surface is perfectly horizontal up to the solid-liquid interface (Cwikel et al., 2010). Under this condition, the contact angle can be determined, which is the angle of the plate with the flat liquid surface. Comparing with the sessile drop and Wilhelmy plate methods, the flatness of the meniscus 
plays a significant role in the accuracy of the measurement. According to previous studies (Vadgama and Harris, 2007; Cwikel et al., 2010), it is not easy to detect the difference between advancing and receding contact angles based on this method.

\section{EXPERIMENTAL SET-UP}

\subsection{Nucleate Pool Boiling Experiments}

The experimental set-up for the thermal study is shown in Fig. 5. It consists of a condensation section (see Fig. 5(a)) and a main test section (see Fig. 5(b)). In the main test section, a Ø11.2mm $\times 112 \mathrm{~mm} \mathrm{Mg}$ alloy pipe with pipe wall thickness of $1.4 \mathrm{~mm}$ and thermal conductivity of 125 $\mathrm{W} / \mathrm{m} \cdot \mathrm{K}$ was fixed in the middle of the polytetrafluoroethylene (PTFE) chamber. As a good insulation material, a PTFE chamber was used to minimise the heat loss from the main test section to the ambient. Acetone, ethanol and their mixtures were used as test fluids. In each experiment the main chamber was filled with the test fluid which was boiled on the surface of the heated $\mathrm{Mg}$ alloy tube immersed within the pool. Between experiments, the chamber was cleaned and the $\mathrm{Mg}$ tube replaced. Moreover in order to achieve high accuracy, the entire test rig was well insulated and isolated from the environment.

Fig. 5(b) shows the schematic diagram of the main test section. Five thermocouples and a pressure transducer are indicated in this figure. To monitor the tube surface temperature, three thermocouples were fixed onto the $\mathrm{Mg}$ alloy pipe surface, with a spacing of $30 \mathrm{~mm}$. One thermocouple was submerged within the liquid to measure the liquid phase temperature; the other was placed above the liquid surface level in order to measure the temperature reading of the vapour phase. Due to the chemical and physical properties of the $\mathrm{Mg}$ alloy and the working fluids, common methods such as soldering or welding are not suitable for fixing the thermocouples onto the $\mathrm{Mg}$ alloy surface, therefore PTFE tape and small clamps were used to fix these thermocouples in position and monitor and prevent the thermocouple lead wire going into the working fluid. A pressure transducer was used to monitor the system pressure. To keep a s table boiling point during the experiments, the stability of pressure must be ensured; therefore a vessel bypass was also connected to the pressure transducer. When the specified system pressure was exceeded the excess pressure was released into the vessel allowing the reading to returns to the required value.

To heat the tube surface a single cartridge heater was inserted into the $\mathrm{Mg}$ tube. Considering the effective length of a heater cartridge; to ensure uniform heating of the pipe surface, a custom designed cartridge with length of $110 \mathrm{~mm}$, diameter of $5 / 8$ ", voltage of $24 \mathrm{~V}$, and power of $150 \mathrm{~W}$ was used. A counter flow heat exchanger was used to condense the vapour back to a liquid.

The mixture was prepared based on liquid volume, and then filled into the PTFE chamber. The following steps were used to degas and deliver the mixture: (1) provided two substances (acetone and ethanol) in separate containers; (2) conveyed ethanol after acetone from its container into the measuring tank: During mixing the tanks, were weighed to ensure the correct fill quantity of each fluid was inserted. The fluids were stirred within the tank in order to mix and degas them; (3) finally the mixture was pumped into the test chamber using a process valve to control the delivery and isolate the system. The properties of pure acetone and ethanol, corresponding to the experimental pressure of 1.01 bar, are shown in Table 1 . The mixtures started to boil around the $\mathrm{Mg}$ alloy pipe surface at surface temperatures of $90^{\circ} \mathrm{C}$. The vaporised mixture flowed to the condensation section, condensed back to a liquid and then returned by gravity to the main test chamber. To maintain the required experimental pressure, the chiller supply temperature was adjusted to enhance condensation heat transfer in order to eliminate pressure overshoot. During the whole boiling process the test section and the condensation section were isolated from the environment.

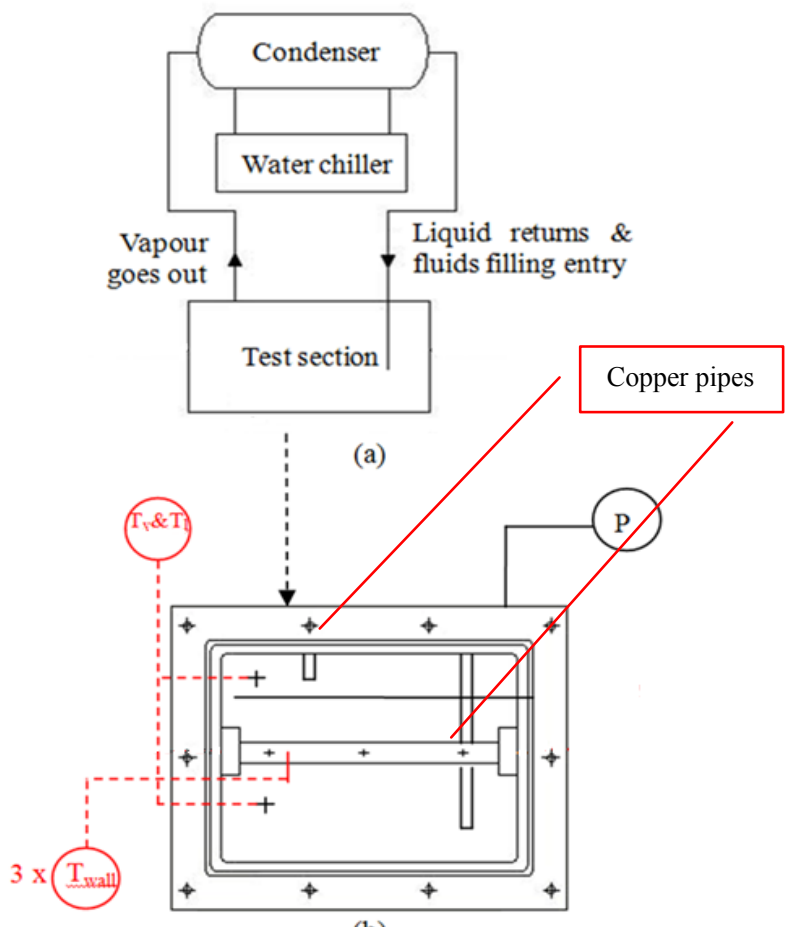

(b)

Fig. 5 Experimental set-up: (a) Sketch of test rig; (b) Main test section.

Table 1 Properties of pure ethanol and acetone.

\begin{tabular}{|l|l|l|l|}
\hline Property & Unit & Ethanol & Acetone \\
\hline Chemical formula & - & $\mathrm{C}_{2} \mathrm{H}_{6} \mathrm{O}$ & $\mathrm{C}_{3} \mathrm{H}_{6} \mathrm{O}$ \\
\hline Molecular weight & $\mathrm{g} / \mathrm{mol}$ & 46 & 58 \\
\hline Density & $\mathrm{g} / \mathrm{cm}^{3}$ & 0.79 & 0.79 \\
\hline Properties under the condition of 1 atm & $\mathrm{K}$ & 329.2 \\
\hline Boiling point & $\mathrm{K}$ & 351.4 & 508.1 \\
\hline Critical temperature & $\mathrm{K}$ & 614.9 & 4700 \\
\hline Critical pressure & $\mathrm{kPa}$ & 6140 & \\
\hline
\end{tabular}

\subsection{Wettability Study - Contact Angle Measurements}

In this study, the contact angles of droplets of a total of 11 working fluids on a flat magnesium alloy surface were measured at $20^{\circ} \mathrm{C}$ room temperature using contact angle measurement apparatus (KSVCAM200). Fig. 6 presents the contact angle measurement apparatus, which mainly consists of a spring, a high-speed camera and a substrate for observing the surface. Working fluids are filled into several syringes and then fixed onto the apparatus. Due to the volatility of acetone and ethanol, the delivery of droplets must be from a point sufficiently close to the substrate, to avoid the kinetic component and prevent the volatility of the liquid. Under this condition, the perturbation to the droplets was minimised while withdrawing the delivery needle. This type of method has also been mentioned in previously reported works (Carey, 2008; Erbil et al., 1999). Throughout these measurements, a constant droplet volume of $2 \mu 1$ was delivered onto the metal substrate through a needle. A camera captured the images immediately and was used for static contact angle calculations based on Young's model. Although on the polished metal surface generated mirror images of the measured droplets (see Fig. 7), measurements were taken from the reference line (see red lines in Fig. 7) on both of the left and right sides of the droplet surface. 


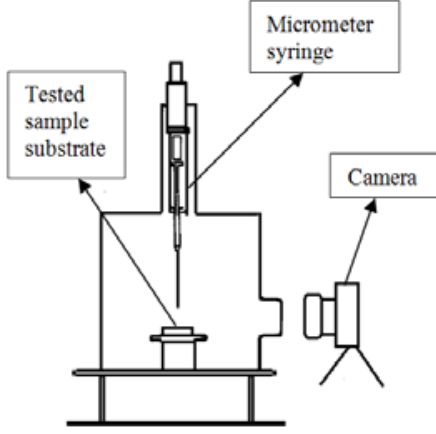

(a)

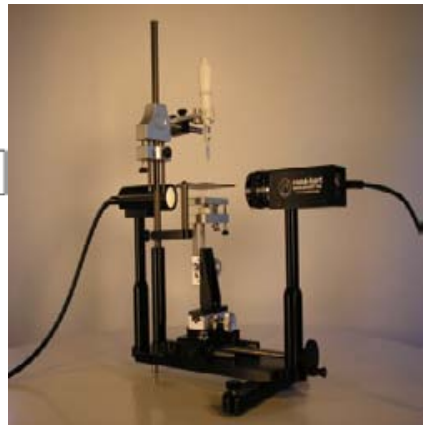

(b)
Fig. 6 (a) Sketch of CA measurement apparatus; (b) Actual photo of the apparatus.

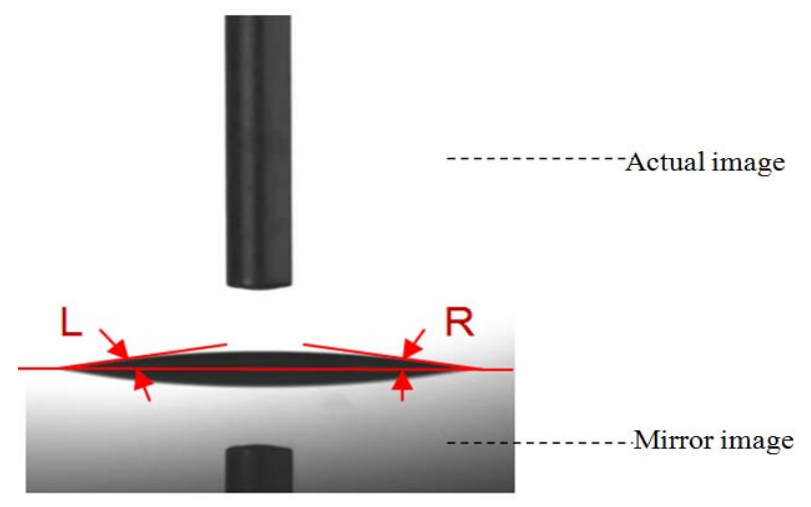

Fig. 7 Digital image of CA measurement.

\section{RESULTS AND DISCUSSIONS}

\subsection{Pool boiling results}

\subsubsection{Pool boiling tests on mixtures}

Three groups of tests are conducted in the present nucleate pool boiling experiments based on the working fluids, namely, pure acetone, pure ethanol and their mixtures, respectively, under pressure of 1.01 bar. The mixtures were prepared with $10 \%$ differences of concentration as are listed in Table 2. The system pressure was monitored using the pressure transducer. As surface heat flux was increased the rate of evaporation / vapour pressure increased. The rate of condensation was controlled to balance the system and maintain the operating pressure. The data obtained based on the increasing heat flux.

Table 2 Mixtures at difference concentration (\%).

\begin{tabular}{|c|c|c|}
\hline Mixtures & Acetone $\widetilde{\boldsymbol{X}}_{1}$ & Ethanol $\widetilde{\boldsymbol{X}}_{2}$ \\
\hline Mixture 1 & 0.9 & 0.1 \\
\hline Mixture 2 & 0.8 & 0.2 \\
\hline Mixture 3 & 0.7 & 0.3 \\
\hline Mixture 4 & 0.6 & 0.4 \\
\hline Mixture 5 & 0.5 & 0.5 \\
\hline Mixture 6 & 0.4 & 0.6 \\
\hline Mixture 7 & 0.3 & 0.7 \\
\hline Mixture 8 & 0.2 & 0.8 \\
\hline Mixture 9 & 0.1 & 0.9 \\
\hline
\end{tabular}

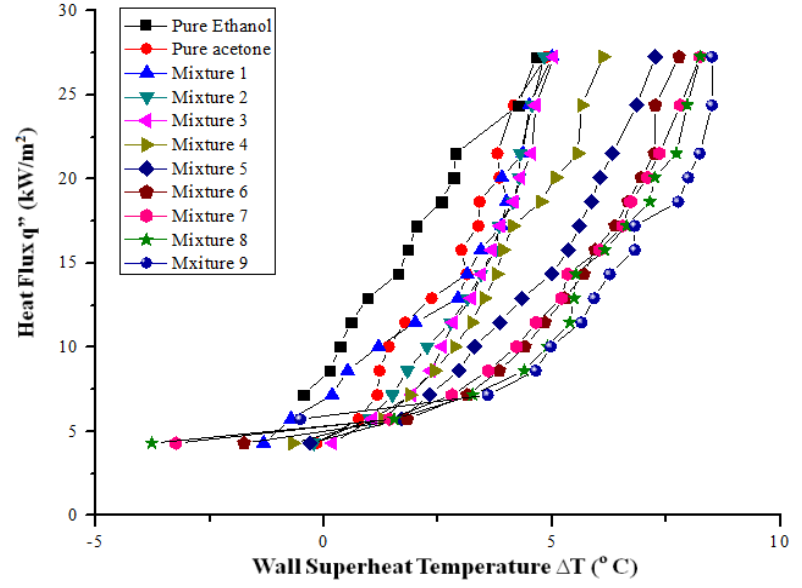

Fig. 8 Heat flux (q") versus wall superheat $\left(\Delta \mathrm{T}_{\mathrm{s}}\right)$ for pure acetone, pure ethanol, and their mixtures.

Fig. 8 shows boiling curves of both pure fluids and their mixtures. All data shown was obtained under the conditions of wall superheat temperature up to $8-9^{\circ} \mathrm{C}$. Comparing the curves of pure fluids with their mixtures, it can be seen that at the same wall superheat temperature, the pure liquids present better heat transfer performance, which can achieve higher heat flux. The heat flux increases almost linearly with wall superheat. For the mixtures, although the performance of the acetone/ethanol mixtures degraded due to the volatile component (acetone), as concentration reduced from $90 \%$ to $10 \%$, the general trend of the results are quite close. Referring to Fig. 2, for acetone/ethanol mixtures, the change of boiling curve happened around $2.3^{\circ} \mathrm{C}$ of super heat.

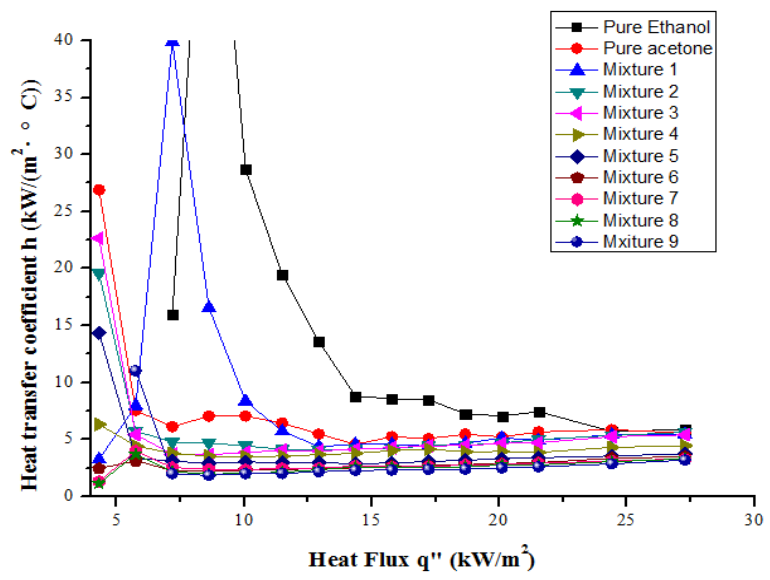

(a) Heat transfer coefficient maximum scale value upto $40 \mathrm{~kW} /\left(\mathrm{m}^{2} \cdot{ }^{\circ} \mathrm{C}\right)$

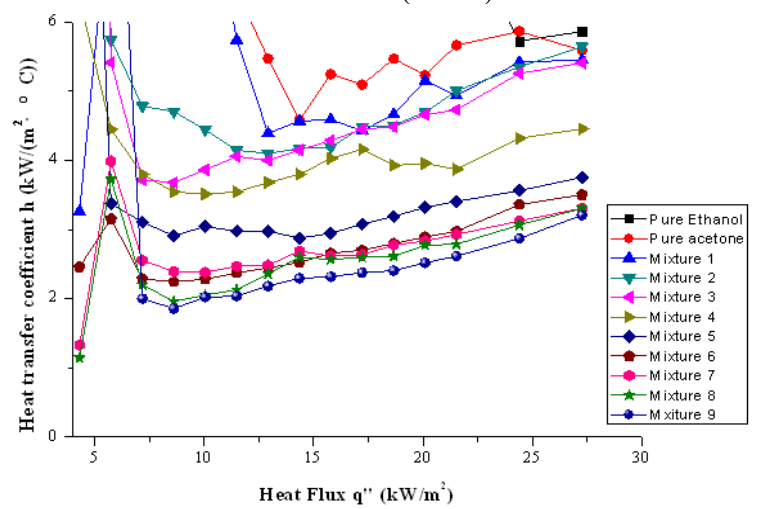

(b) Heat transfer coefficient maximum scale value upto $6 \mathrm{~kW} /\left(\mathrm{m}^{2} \cdot{ }^{\circ} \mathrm{C}\right)$. Fig. 9 Average heat transfer coefficient diagram based on experiments. 
The average heat transfer coefficients of different working fluids are shown in Fig. 9. It is obvious that the pure working fluids have higher heat transfer coefficients than the mixtures in pool nucleate boiling of different heat flux and heat transfer coefficients rise with the increase of heat flux as well. In Fig. 9(a), it can be seen that their individual heat transfer coefficients obtain a "p eak" at the very beginning when the heat flux is at very low level and then indicates an increasing trend. Thus, during the natural convection stage, heat transfer coefficients are quite small. When more heat is provided bubbles are formed on the hot pipe surface.

Although boiling was initiated the wall temperature was still lower than the saturated boiling point, so that subcooled boiling continued up to a surface heat flux of approximately $6 \mathrm{~kW} / \mathrm{m}^{2}$. The "peak" value of heat transfer coefficient was obtained when the wall temperature approaced to the saturation value. After the saturation boiling point, the system needed less time for adjustment to maintain stable nucleate boiling (see Fig. 10 (b) to (e)). Therefore, in the Fig. 9, there is "peak" or slanting at the beginning. Moveover, for pure working fluids, it takes a longer time to achieve saturation boiling state from subcooled boiling process; under the same operation condition (same heating method, recorded starting from $\mathbf{1 0}$ lower than its saturation point), pure acetone liquid took about 2900s to achieve saturation boiling and nearly 4000 s for ethanol to achieve saturation boiling. However, for the binary mixtures, the subcooled boiling period was much shorter and reduced with decreasing concentration of acetone. For example, mixture 1 with of $90 \%$ acetone took around 2800 s and mixture 9 with $10 \%$ acetone took approximately 2250 s. According to the curves presented in Fig. 9(b), it is obvious to see that when the concentration (or mole fraction) of volatile component increases, it requires more heat input to achieve the nucleate pool boiling.

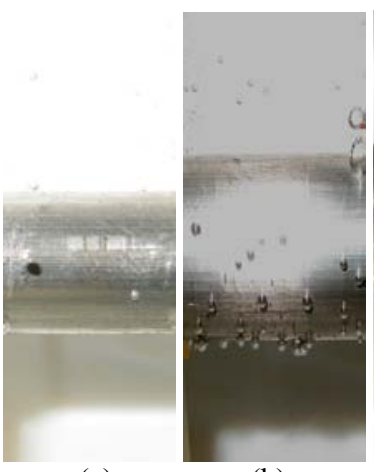

(a)

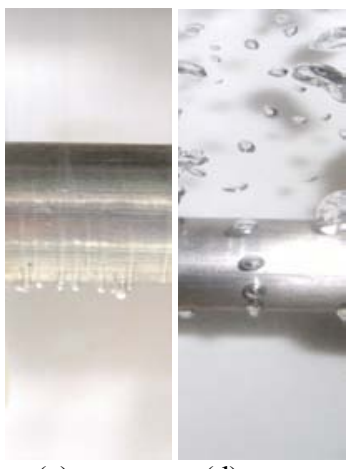

(d)

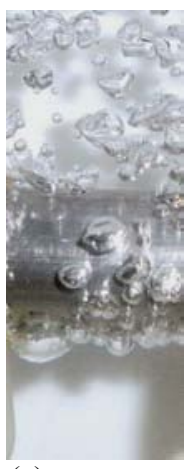

(e)
Fig. 10 Visualised boiling process of pure ethanol on $\mathrm{Mg}$ alloy surface: (a) Natural convection, (b) ONB, (c) Nucleate boiling at low q", (d) Partial nucleate boiling, (e) Partial nucleate boiling.

Fig. 10 presents a process of bubble growth during the pool boiling. Natural convection is shown in Fig. 10(a), in which few bubbles can be seen in the pool. When heat flux increases, it provides sufficient wall superheat on the surface and vapour nucleation occurs on the $\mathrm{Mg}$ alloy surface with individual bubbles growing from the cavities of the metal surface. Fig. 10(b) indicates such situation, when nucleate boiling (ONB) occurs. In Fig. 10(c), small bubbles coalesced and form a bubble stream escaping from the heated surface. With more power input from the heater cartridge, more bubbles are generated at active nucleation site. Due to coalescence of small bubbles, the vapour structure changes, with bigger bubbles as sown in Fig. 10(d). As the heat flux kept increasing, nucleate boiling became violent as well. From Fig. 10(e), it can be seen that small bubbles formed vapour patches or columns immediately around heated surface and then escaped into pool. Although current experiments have not achieved very high heat flux, the whole process of bubble growth from natural convection to nucleate pool boiling is clearly shown in Fig. 10.

\subsubsection{Characteristics of binary mixture boiling}

When boiling a pure liquid, the liquid and vapour compositions are kept the same and then the whole boiling process can be controlled by heat transfer. In contrast, when mixtures boil, the vapour-liquid phase equilibrium characteristics allow the vapour and liquid phases to be at different compositions. The composition is an important factor affecting the heat transfer process. Due to variety of compositions, a number of physical properties of mixture also change as well.

As mentioned in previous session, the heat transfer coefficient of a binary mixture is defined as Eq. (1):

$$
h_{b l}=\frac{q^{\prime \prime}}{\left[T_{W}-T_{b p}\left(P_{l}, \widetilde{x}_{l}\right)\right]}
$$

and the ideal heat transfer coefficient can be calculated by Eq. (2):

$h_{b l i}=h_{b 1} \widetilde{x}_{l}+h_{b 2}\left(1-\widetilde{x}_{l}\right)$

According to the results presenting in Fig. 11, almost all experimental results of heat transfer coefficients of binary mixtures are less than the ideal values, except at two points in Fig. 11(a) and (b) respectively. This is because the heat fluxes were not sufficient high to achieve saturated boiling when the data was taken. Thus, relevant heat transfer coefficients did not become stable, which present above the ideal value curves. In Fig. 11, the ideal values are indicated by dashed line and experimental data are expressed by the red curves. Fig. 11(a) to (m) shows heat transfer coefficients with heat flux increasing from 7.2 $\mathrm{kW} /\left(\mathrm{m}^{2} \cdot{ }^{\circ} \mathrm{C}\right)$ to $27.3 \mathrm{~kW} /\left(\mathrm{m}^{2} \cdot{ }^{\circ} \mathrm{C}\right)$.

It can be seen that as for binary mixtures, the experimental results are lower than the ideal situation for low heat flux conditions (see Fig. 11(a) to (e)). Moreover, the trend of heat transfer coefficients is not linear and mixtures provide lower values than the pure liquids. When the concentration of the volatile component is increased, the binary mixture can achieve higher heat transfer coefficients. When the heat flux increased up to $14.4 \mathrm{~kW} /\left(\mathrm{m}^{2} \cdot{ }^{\circ} \mathrm{C}\right)$, the difference of heat transfer coefficients between pure liquids and mixtures is reduced. Also the heat transfer coefficient does not change obviously until the heat flux above $21.5 \mathrm{~kW} /\left(\mathrm{m}^{2} \cdot{ }^{\circ} \mathrm{C}\right)$ (see Fig. 11(f) to (k)). In Fig. 11(l) and (m), it also can be found that the difference of heat transfer coefficients between pure ethanol and acetone gets small, when heat flux rising to 24.4 and $27.3 \mathrm{~kW} /\left(\mathrm{m}^{2} \cdot{ }^{\circ} \mathrm{C}\right)$ and the trends of idea curve turn horizontal. However, in Fig. 11(1), the heat transfer coefficient of ethanol is slightly lower than the value of acetone, which is not correct and might be caused by error during the experiment.

Regarding these changes in the heat flux they can be explained by pool boiling regimes. At the beginning, nature convection dominates and then nucleate boiling occurs. To produce nucleate boiling in ethanol needs a high heat flux due to its higher boiling point. Thus, at same low heat flux, ethanol only reaches lower wall superheat temperature, and then it gives higher heat transfer coefficient at ONB stage. When nucleate boiling occurs in ethanol pool, stable heat transfer coefficient is achieved and then the values for pure ethanol and acetone get close. Therefore, in Fig. 11, it can be summarised that binary mixtures of acetone and ethanol present lower heat transfer coefficient than pure liquids at uniform pressure and heat flux.

\subsection{Contact angle measurements}

The experimental contact angles for droplets of acetone, ethanol and the nine mixtures shown in Table 2 onto a $\mathrm{Mg}$ alloy plate are presented in Table 3. To ensure reproducibility and accuracy, each contact angle experiment was repeated five times under the same conditions and the average contact angle calculated to produce the final value.

Table 3 presents results of 2 purities (acetone and ethanol) and 9 of their mixtures on the $\mathrm{Mg}$ alloy surface, giving the average contact angle of pure acetone as $12.7^{\circ}$, and $17.6^{\circ}$. Meanwhile, regarding their mixtures, the contact angles are in range of 17.6 25.6 . 

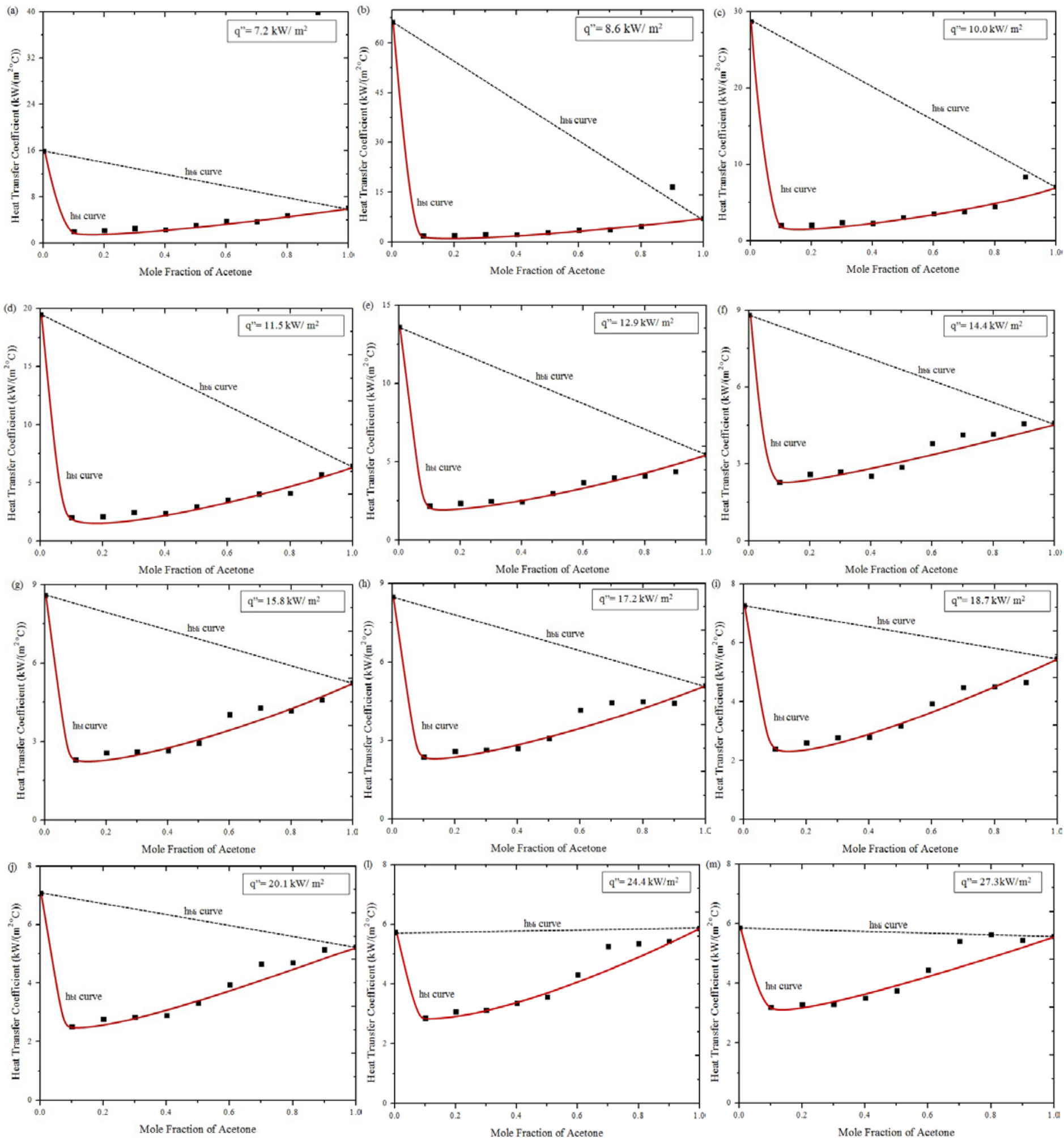

Fig. 11 Qualitative variation of nucleate boiling heat transfer coefficient with bulk liquid mole fraction of acetone mixture at $101.3 \mathrm{kPa}$.

Fig. 12 presents the experimental data of left, right and combined average contact angles each of the acetone/ethanol mixtures from $0 \%$ to $100 \%$. The Red line is a polynomial fit of combined average contact angle with polynomial order of 5 . It gives the general trend of binary mixture contact angles that the purities have smaller contact angles than mixtures. In other words, on the same magnesium alloy surface, both pure acetone and ethanol provide better wetting phenomenon than their mixtures.

\section{CONCLUSIONS}

Based on the fundamental studies on b oth thermal and wettability, experimental studies on poo 1 nucleate boiling and contact angle measurements of pure acetone, ethanol and their mixtures on magnesium alloy pipe have been carried out. The investigations have indicated: 
(1) Pure ethanol presents a better heat transfer performance than pure acetone, which can achieve ah igher heat transfer coefficient by a uniform heat flux.

(2) Pure working fluids show higher heat transfer coefficients when operating conditions are the same, such as uniform heat flux and pressure;

(3) Comparing nine acetone/ethanol mixtures, with increasing volatile component concentrations, the mixture can get a higher value of the heat transfer coefficient.

(4) Also, under the same pressure and heat flux, the heat transfer coefficient of a binary mixture does not present a linear curve against mole fractions. Less volatile components give the maximum value of heat transfer coefficient, followed by purity of volatile components.

(5) Two pure working fluids (acetone and ethanol) and nine of their mixtures gave low values of combined average contact angles. In other words, they presented good wettability on polished magnesium alloy surfaces.

In conclusion, the fundamental studies proved that both pure acetone \& ethanol and their mixtures can be the potential working fluids of magnesium alloy heat pipes. Comparing the purities with binary mixtures, it can be concluded that pure liquid droplets can provide a better hydraulic phenomenon when placed in contact with magnesium alloy surfaces.

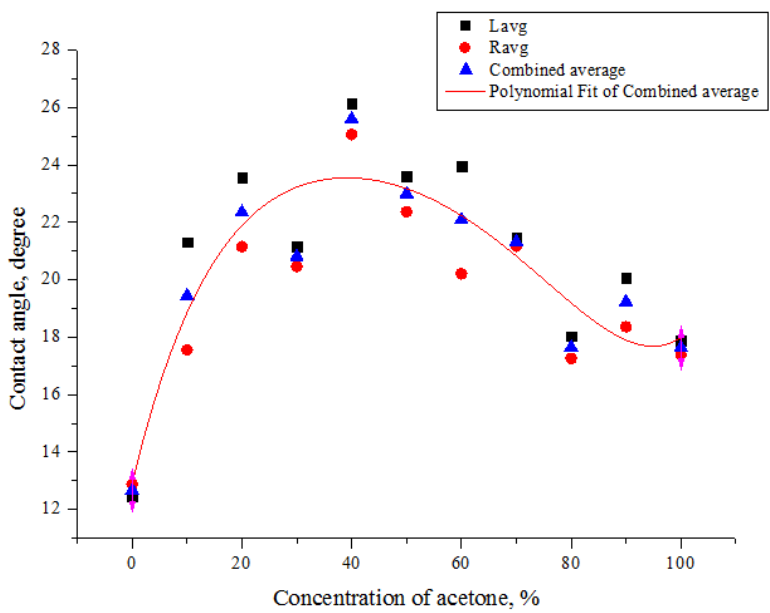

Fig. 12 CA measurements of mixtures by different concentrations.

\section{ACKNOWLEDGEMENTS}

This research work is supported by the University of Nottingham, UK and Thermacore Europe Ltd. (UK).

\section{NOMENCLATURE}

$\begin{array}{ll}A & \text { area }\left(\mathrm{m}^{2}\right) \\ E & \text { total energy }(\mathrm{J}) \\ F & \text { force }(\mathrm{N}) \\ h & \text { heat transfer coefficient } \\ & {\left[\mathrm{W} /\left(\mathrm{m}^{2} \cdot \mathrm{K}\right)\right]} \\ m & \text { mass }(\mathrm{kg}) \\ P & \text { pressure }(\mathrm{Pa}) \\ \Delta P & \text { pressure difference }(\mathrm{Pa}) \\ \Delta P_{c} & \text { capillary pressure drop }(\mathrm{Pa}) \\ q^{\prime \prime} & \text { heat flux }\left(\mathrm{W} / \mathrm{m}^{2}\right) \\ T & \text { temperature }\left({ }^{\circ} \mathrm{C}\right) \\ T_{b p} & \text { bubble point temperature }\left({ }^{\circ} \mathrm{C}\right) \\ V & \text { volume }\left(\mathrm{m}^{3}\right)\end{array}$

Greek Symbols

$\Theta \quad$ contact angle $\left({ }^{\circ}\right)$

$\rho \quad$ density $\left(\mathrm{kg} / \mathrm{m}^{3}\right)$

$\sigma \quad$ surface tension $(\mathrm{N} / \mathrm{m})$

Subscripts

bl bulk liquid

l liquid

lv liquid-vapour

sl solid -liquid

sv solid-vapour

w wall

\section{REFERENCES}

Avedesian, M. and Baker, H. eds, 1999, ASM specialty handbook: Magnesium and magnesium alloys, Cleveland: ASM International, the materials information society.

Bejan, A. and Kraus, A. Eds., 2003, Heat Transfer Handbook, John Wiley\&Sons, New York.

Carey, V., 2008, Liquid-Vapor Phase-Change Phenonmena, $2^{\text {nd }}$ ed., Taylor \& Francis Group.

Collier, J. and Thome J., 1994, Convective Boiling and Condensation, Oxford Science Publications.

Cwikel, D., Zhao, Q., Liu, C., Su, X. and Marmur A., 2010, "Comparing contact angle measurements and surface tension assessments of solid surfaces," Langmuir, 26(19), 15289-15294.

http://dx.doi.org/10.1021/la1020252

Erbil, H.Yildirim, McHale, G., Rowan, S. M. and Newton, M. I., 1999, "Determination of the receding contact angle of sessile drops on polymer surfaces by evaporation," Langmuir, 15(21), 7378-7385.

http://dx.doi.org/10.1021/la9900831

Table 3 Measured contact angle values on magnesium alloy surface @, 20 $\mathrm{C}$

\begin{tabular}{|c|c|c|c|c|c|c|c|c|c|c|c|c|c|}
\hline \multirow[t]{2}{*}{ Working fluids } & \multicolumn{2}{|c|}{ Analysis 1} & \multicolumn{2}{|c|}{ Analysis 2} & \multicolumn{2}{|c|}{ Analysis 3} & \multicolumn{2}{|c|}{ Analysis 4} & \multicolumn{2}{|c|}{ Analysis 5} & \multirow[t]{2}{*}{$\mathbf{L}_{\text {arg }}$} & \multirow[t]{2}{*}{$\mathbf{R}_{\text {avg }}$} & \multirow[t]{2}{*}{ Average } \\
\hline & $\mathbf{L}$ & $\mathbf{R}$ & $\mathbf{L}$ & $\mathbf{R}$ & $\mathbf{L}$ & $\mathbf{R}$ & $\mathbf{L}$ & $\mathbf{R}$ & $\mathbf{L}$ & $\mathbf{R}$ & & & \\
\hline Pure acetone & 13.3 & 13.5 & 12.5 & 11.7 & 12.1 & 12.7 & 12.9 & 14.2 & 11.5 & 12.3 & 12.5 & 12.9 & 12.7 \\
\hline Pure ethanol & 15.7 & 15.9 & 17.8 & 17.7 & 20.4 & 19.4 & 18.2 & 17.6 & 17.1 & 16.4 & 17.9 & 17.4 & 17.6 \\
\hline Mixture $(10 \%$ acetone $+90 \%$ ethnaol $)$ & 16.5 & 16.2 & 23.4 & 20.2 & 21.6 & 12.5 & 28.1 & 23.5 & 16.9 & 15.3 & 21.3 & 17.6 & 19.4 \\
\hline Mixture (20\% acetone $+80 \%$ ethnaol) & 19.0 & 20.8 & 23.3 & 21.8 & 25.3 & 23.3 & 30.7 & 18.5 & 19.4 & 21.5 & 23.5 & 21.1 & 22.3 \\
\hline Mixture (30\% acetone $+70 \%$ ethnaol) & 23.9 & 23.0 & 20.3 & 19.7 & 21.2 & 21.2 & 18.8 & 17.6 & 21.6 & 20.8 & 21.2 & 20.5 & 20.8 \\
\hline Mixture $(40 \%$ acetone $+60 \%$ ethnaol $)$ & 25.2 & 24.5 & 30.6 & 27.8 & 19.5 & 20.8 & 31.7 & 29.7 & 23.7 & 22.5 & 26.1 & 25.1 & 25.6 \\
\hline Mixture $(\mathbf{5 0} \%$ acetone $+\mathbf{5 0} \%$ ethnaol $)$ & 26.1 & 25.3 & 24.9 & 24.8 & 21.6 & 20.9 & 22.1 & 20.7 & 23.3 & 20.1 & 23.6 & 22.4 & 23.0 \\
\hline Mixture $(60 \%$ acetone $+40 \%$ ethnaol $)$ & 23.5 & 23.0 & 28.1 & 18.6 & 18.6 & 20.0 & 25.9 & 17.9 & 23.7 & 21.5 & 24.0 & 20.2 & 22.1 \\
\hline Mixture $(70 \%$ acetone $+\mathbf{3 0} \%$ ethnaol) & 17.4 & 20.7 & 23.1 & 20.1 & 20.7 & 17.6 & 24.9 & 26.4 & 21.2 & 21.0 & 21.5 & 21.2 & 21.3 \\
\hline Mixture $(80 \%$ acetone $+20 \%$ ethnaol $)$ & 19.2 & 16.2 & 16.6 & 14.6 & 20.5 & 19.9 & 16.8 & 17.7 & 17.1 & 17.9 & 18.0 & 17.3 & 17.6 \\
\hline Mixture $(90 \%$ acetone $+10 \%$ ethnaol $)$ & 25.1 & 22.1 & 16.7 & 15.3 & 19.5 & 19.1 & 20.3 & 18.8 & 18.7 & 16.6 & 20.1 & 18.4 & 19.2 \\
\hline
\end{tabular}


Fujita, Y. and Tsutsui, M., 2004, "Nucleate boiling of two and threecomponent mixtures," International Journal of Heat and Mass Transfer, 47(21), 4637-4648.

http://dx.doi.org/10.1016/j.ijheatmasstransfer.2003.09.039

Gao, N., Yan, Y.Y, 2009, "Modelling Superhydrophobic Contact Angles and Wetting Transition", Journal of Bionic Engineering, 6(4), $335-340$

http://dx.doi.org/10.1016/S1672-6529(08)60135-3

Gorenflo, D., Gremer F., Danger, E., Luke, A., 2001, "Pool boiling heat transfer to binary mixture with miscibility gap experimental results of a horizontal copper tube with $4.35 \mathrm{~mm}$ O.D," Experimental Thermal and Fluid Science, 25(5), 243-254.

http://dx.doi.org/10.1016/S0894-1777(01)00072-3

Heiskanen, V., Marjanen, K. and Kallio P., 2008, "Machine vision based measurement of dynamic contact angles in microchannel flows," Journal of Bionic Engineering, 5(4), 282-290. http://dx.doi.org/10.1016/S1672-6529(08)60172-9

Hewitt, G.F., Shires G.L. and Bott, T.R., 1993, Process Heat Transfer. CRC Press, Inc.

Hoa, C., Demolder, B. and Alexandre, A., 2003, "Roadmap for developing heat pipes for alcatel space's satellites," Applied Thermal Engineering, 23(9), 1099-1108.

http://dx.doi.org/10.1016/S1359-4311(03)00039-5

Inoue, T., Monde, M. and Teruya, Y., 2002, "Pool boiling heat transfer in binary mixtures of ammonia/water", International Journal of Heat and Mass Transfer, 45(22), 4409-4415.

http://dx.doi.org/10.1016/S0017-9310(02)00153-9

Ji, C.Y., and Yan Y.Y., A, 2008, "Molecular dynamics simulation of liquid-vapour-solid system near triple-phase contact line of flow boiling in a microchannel," Applied Thermal Engineering, 28 (2-3), 195-202, http://dx.doi.org/10.1016/j.applthermaleng.2007.03.029

Krishnan, A., Liu, Y.H., Cha, P., Woodward, R., Allara, D. and Vogler, E.A., 2005, "An evaluation of methods for contact angle measurement," Colloids and Surfaces B: Biointerfaces, 43(2), 95-98. http://dx.doi.org/10.1016/j.colsurfb.2005.04.003

$\mathrm{Ku}$, Hsu-Chen and Tu, Chein-Hsiun, 2005, "Isobaric vapour-liquid equilibria for mixtures of acetone, ethanol, and 2,2,4-trimethylpentane at 101.3kPa," Fluid Phase Equilibria, 231, 99-108.

http://dx.doi.org/10.1016/j.fluid.2005.01.007

Markar, G. and Kruger, J., 1993, "Corrosion of magnesium," International Materials Reviews, 38(3), 138-153.

Neumann, A.W.G. and Good, R.J., 1979, "Techniques of measuring contact," in: R.J. Good, R.R. Strongberg (Eds), Surface and Colloid Science, Plenum Press, New York.

Neve, R.S. Yan, Y.Y., 1996, "Enhancement of heat exchanger performance using combined electrohydrodynamic and passive methods", International Journal of Heat and Fluid Flow, 17(4), 403409. http://dx.doi.org/10.1016/0142-727X(95)00016-J

Ochterbeck, J.M., 2003 "Heat pipes," in: Bejan A. and Kraus, A.D., eds. Heat Transfer Handbook, John Wiley \& Sons, New York.
Rao, V. and Balakrishnan, A., 2004, "Heat transfer in nucleate pool boiling of multicomponent mixtures," Experimental Thermal and Fluid Science, 29(1), 87-103.

http://dx.doi.org/10.1016/j.expthermflusci.2004.02.001

Reay, D. and Kew, P., 2006, Heat Pipes: Theory, Design and Applications, $5^{\text {th }}$ ed., Butterworth-Heinemann, an imprint of Elsevier.

Rosenfeld, J. and Zarembo S., 2001, "Final report of ultra-lightweight magnesium heat pipes for spacecraft thermal management", Thermacore International Inc.

Shang, J. Y., Flury, M., Harsh, J. B. and Zollars, R. L., 2008, Comparison of different methods to measure contact angles of soil colloids, Journal of Colloid and Interface Science, 328(2), 299-307. http://dx.doi.org/10.1016/j.jcis.2008.09.039

Táboas, F., Vallès, M., Bourouis, M. and Coronas A., 2007, "Pool boiling of ammonia/water and its pure components: comparison of experimental data in the literature with the predictions of standard correlations", International Journal of Refrigeration, 30(5), 778-788. http://dx.doi.org/10.1016/j.ijrefrig.2006.12.009

Thome, J.R., 1987, "Enhanced boiling of mixtures," Chemical Engineering Science, 42(8), 1909-1917. http://dx.doi.org/10.1016/0009-2509(87)80137-9

Vadgama, B. and Harris, D.K., 2007, "Measurements of the contact angle between R134a and both aluminium and copper surfaces," Experimental Thermal and Fluid Science, 31(8), 979-984. http://dx.doi.org/10.1016/j.expthermflusci.2006.10.010

Yan, Y.Y. and Ji, C.Y., 2008, "Molecular dynamics simulation of behaviours of non-polar droplets merging and interactions with hydrophobic surfaces," Journal of Bionic Engineering, 5(4), 271-281. http://dx.doi.org/10.1016/S1672-6529(08)60171-7

Yang, X. and Yan, Y.Y., 2011, "Molecular dynamics simulation for microscope insight of water evaporation on a heated magnesium surface," Applied Thermal Engineering, 31(5), 640-648. http://dx.doi.org/10.1016/j.applthermaleng.2010.08.019

Yang, X., Yan,, Y.Y. and Mullen, D., 2012, "Recent developments of lightweight, high performance heat pipes", Applied Thermal Engineering. 33-34, 1-14.

http://dx.doi.org/10.1016/j.applthermaleng.2011.09.006

Zhang, L.Q., Gong, M.Q., Zhang, Y., Li, P., Wu, J.F. and Xu, L., 2007, "Nucleate pool boiling heat transfer measurements of HC170/HFC23 system," International Communications in Heat and Mass Transfer, 34(3), 277-284.

http://dx.doi.org/10.1016/j.icheatmasstransfer.2006.12.005

Jungickel, H., Wassilew, P. and Kraus, W.E., 1980, "Investigations on the heat transfer of boiling binary refrigerant mixtures," International Journal of Refrigeration, 3(3), 129-133. http://dx.doi.org/10.1016/0140-7007(80)90092-4

Zhao, Y.H., Diao Y.H. and Takaharu T., 2008, "Experimental investigation in nucleate pool boiling of binary refrigerant mixtures," Applied Thermal Engineering, 28(2-3): 110-115. http://dx.doi.org/10.1016/j.applthermaleng.2007.03.035 